\title{
BMJ Open Prevalence of olfactory dysfunction and quality of life in hospitalised patients 1 year after SARS-CoV-2 infection: a cohort study
}

\author{
Hui Qi Mandy Tan (D) ,",2 Alfonso Luca Pendolino (D) ,", Peter J Andrews (D) , ,34 \\ David $\mathrm{Choi}^{2}$
}

To cite: Tan HQM, Pendolino AL, Andrews PJ, et al. Prevalence of olfactory dysfunction and quality of life in hospitalised patients 1 year after SARS-CoV-2 infection: a cohort study. BMJ Open 2022;12:e054598. doi:10.1136/ bmjopen-2021-054598

- Prepublication history and additional supplemental material for this paper are available online. To view these files, please visit the journal online (http://dx.doi.org/10.1136/ bmjopen-2021-054598).

Received 16 June 2021 Accepted 01 December 2021

D) Check for updates

(c) Author(s) (or their employer(s)) 2022. Re-use permitted under CC BY-NC. No commercial re-use. See rights and permissions. Published by BMJ.

${ }^{1}$ UCL Medical School, University College London, London, UK ${ }^{2}$ Department of Neurosurgery, National Hospital for Neurology and Neurosurgery, London, UK ${ }^{3}$ Department of Ear, Nose and Throat, Royal National ENT \& Eastman Dental Hospitals, London, UK

${ }^{4} \mathrm{UCL}$ Ear Institute, University College London, London, UK

Correspondence to Hui Qi Mandy Tan; mandy.tan.18@ucl.ac.uk

\section{ABSTRACT}

Objectives To determine the long-term prevalence of olfactory and/or gustatory dysfunction $(0 \mathrm{D} \pm \mathrm{GD})$, associated risk factors and impact on quality of life (QoL) in previously hospitalised patients with COVID-19 1 year after infection.

Design A single-centre cohort study.

Setting Patients admitted at a large central London hospital with COVID-19 infection between 10 February 2020 and 22 May 2020.

Participants 150 adult subjects with previously confirmed SARS-CoV-2 infection were recruited between 10 December 2020 and 29 January 2021. Participants were predominantly male $(102 / 150,68.0 \%)$; mean age $58.0 \pm 15.9$ years and $41.2 \%(56 / 136)$ were of black, Asian and minority ethnic backgrounds.

Main outcome measures EQ-5D-5L values and SinoNasal Outcome Test-22 (SNOT-22) scores.

Results Long-term prevalence of $\mathrm{OD} \pm \mathrm{GD}$ was $12.8 \%$ (19/149) at median time of 264.5 days following SARSCoV-2 infection onset. Patients with $\mathrm{OD} \pm \mathrm{GD}$ had a significantly higher median total SNOT-22 score (46.1; Q1-Q3: 23.0-60.0; 95\% Cl 23.0 to 60.0) compared with those without (16.0; Q1-Q3: 5.0-30.5; 95\% Cl 12.0 to 18.0$)(p=0.0002)$, reflecting poorer $Q 0 L$, particularly psychological well-being $(p=0.0004)$, which was not alleviated with time $(p=0.4977)$. Median $E Q-5 D-5 L$ value was not significantly different between patients with OD $\pm \mathrm{GD}(0.70 ; \mathrm{Q} 1-\mathrm{Q} 3: 0.38-0.83 ; 95 \% \mathrm{Cl} 0.38$ to 0.83$)$ and those without (0.83; Q1-Q3: $0.61-0.94 ; 95 \% \mathrm{Cl} 0.75$ to 0.89$)(p=0.0627)$. Age, sex, ethnicity, smoking status, highest $C$ reactive protein value, intubation and ventilation, and oxygen supplementation were not found to influence OD $\pm G D(p>0.05)$.

Conclusions $12.8 \%$ of previously hospitalised patients with COVID-19 in London still report persistent problems with smell or taste up to a year after infection, impacting their QoL. Increased holistic support including psychological therapy and olfactory rehabilitation for affected patients may help to reduce long-term morbidity.

\section{INTRODUCTION}

With over 250 million cases and 5 million deaths recorded worldwide so far, ${ }^{1}$ the COVID-19 pandemic caused by SARS-CoV-2 is
Strengths and limitations of this study

To our knowledge, this is the first study to have determined the long-term prevalence of olfactory and/ or gustatory dysfunction $(\mathrm{OD} \pm \mathrm{GD})$ in a cohort of previously hospitalised patients with COVID-19 at 1 year following infection.

- The use of validated measures allows us to conclude that persistent $\mathrm{OD} \pm \mathrm{GD}$, as a key manifestation of long-COVID, is associated with reductions in patient quality of life and well-being.

- Prevalence of $\mathrm{OD} \pm \mathrm{GD}$ in this study is based on previously hospitalised patients with COVID-19 and may not represent that of mild-to-moderate COVID-19 subjects in the general community, although this allows for important comparisons between different populations.

- Patient-reported outcome measures (PROMs) poorly correlate with psychophysical tests. However, given their good discriminative ability to predict an impaired olfactory function, PROMs still remain of value when psychophysical testing cannot be conducted.

an ongoing global crisis. COVID-19 presentation is highly varied. An estimated $17 \%-20 \%$ of those infected remain asymptomatic, ${ }^{2} 3$ while others can develop a mild-to-moderate disease or severe pneumonia. ${ }^{4}$

According to WHO, 'loss of smell or taste' is considered a less common symptom of COVID-19. However, findings from many studies conducted worldwide have strongly contradicted this, with several reports depicting high prevalence of olfactory and/ or gustatory dysfunction (OD \pm GD) among infected subjects. ${ }^{5-10}$ So far, the long-term prevalence of $\mathrm{OD} \pm \mathrm{GD}$ is unknown, and values determined from the large proportion of studies conducted during the earlier months of the pandemic poorly reflect its persistence and the current proportion of those still affected. Prevalence of OD and GD also vary depending on studied populations, 
between $54.2 \%$ and $70.2 \%$ of the general population with mild-to-moderate symptoms (mean $11.5 \pm 5.7$ days), ${ }^{11}$ $69.2 \%$ and $73.1 \%$ in mild-to-moderate symptomatic healthcare workers (median follow-up of 52 days), ${ }^{9}$ and $5.1 \%$ and $5.6 \%$ in acutely hospitalised patients. ${ }^{12}$ There also remains conflicting data surrounding associated risk factors. Pre-COVID-19 data show that OD is associated with increased morbidity and mortality, ${ }^{13-15}$ and population studies have shown that anosmia is an independent risk factor for a shortened life span. ${ }^{16-20}$ In a study of over 3000 adults, olfactory function was reported to be one of the strongest independent predictors of 5-year mortality, surpassing heart failure, lung disease and even cancer. ${ }^{21}$ COVID-19-related OD presentation has been extensively investigated, but its impact on quality of life (QoL) in the context of COVID-19 has not been fully explored. Therefore, this represents a key area which needs to be addressed to more effectively reduce long-term morbidity.

We conducted a cohort study on previously hospitalised patients with COVID-19 admitted at a central London hospital during the first pandemic wave, to determine the long-term prevalence of $\mathrm{OD} \pm \mathrm{GD}$, potential risk factors and impact on QoL.

\section{METHODS}

A cohort study of previously hospitalised patients with COVID-19 was performed between 10 December 2020 and 29 January 2021 at the National Hospital for Neurology and Neurosurgery (London, UK).

\section{Study population}

Three hundred and fifty-eight patients hospitalised at University College London Hospital with a COVID-19 diagnosis between 10 February 2020 and 22 May 2020 were identified as potentially eligible for this study. Sample size was determined pragmatically based on data available within the medical database at the time of collection. Electronic medical records and laboratory findings were reviewed to verify full adherence to the following inclusion criteria: (1) adults $\geq 18$ years of age, and either (2) laboratory-confirmed SARS-CoV-2 infection, defined as a positive result on reverse transcription PCR analysis of nasopharyngeal swab specimens, or (3) clinically confirmed COVID-19 on the basis of presenting symptoms, in accordance with WHO interim guidance at the time. ${ }^{22}$ Considering the lack of widespread testing in the UK during this studied period of the pandemic, both laboratory and clinical diagnostic criteria were initially included to prevent inadvertent exclusion of eligible participants. Prior to commencement of the study, demographic data including age, sex, ethnicity and smoking status were noted to facilitate investigation into any potential associations. Baseline characteristics and medical status were also recorded to identify ineligible patients (death or patient age $<18$ years).

\section{Outcomes}

Eligible subjects were invited to undertake telephone interviews involving a series of standardised questions from validated questionnaires: the EuroQoL 5-Dimension 5-Level (EQ-5D-5L) ${ }^{23}$ and the Sino-Nasal Outcome Test-22 (SNOT-22). Patients reporting decreased sense of smell/taste in the SNOT-22 were subsequently followed up with an additional smell and taste questionnaire (online supplemental figure 1) designed to capture specific details relating to the type(s) of chemosensory dysfunction experienced. All telephone interviews were conducted in English by the same researcher following a standardised procedure in an effort to minimise interobserver bias. Verbal informed consent was obtained from all participants prior to enrolment in the study.

\section{Statistical analysis}

All statistical analyses were performed using GraphPad Prism V.9.0.1 for macOS (GraphPad Software, San Diego, California, USA). Qualitative variables were presented as frequency and percentages; quantitative variables were summarised as median and IQR or mean \pm SD for normally distributed data. Non-parametric variables were compared using the Mann-Whitney test; data following Gaussian distribution were analysed using the unpaired t-test, with Welch's correction applied to adjust for unequal SDs and variances. Fisher's exact test was used to compare associations between variables in patients with $\mathrm{OD} \pm \mathrm{GD}$ and patients without OD or GD. Linear regression analysis was performed to explore whether SNOT-22 scores changed over time. The $95 \%$ CIs were provided for the reported data where appropriate, and the level of statistical significance was set at a two-sided $\mathrm{p}<0.05$.

\section{Patient and public involvement}

No patients or members of the public were involved in setting the research question or the outcome measures. They were not involved in the study design or conduct, nor were they invited to contribute to the writing, interpretation, reporting or distribution of the results.

\section{RESULTS}

Three hundred and fifty-eight patients previously hospitalised with a COVID-19 diagnosis were identified as potentially eligible for this study. Figure 1 outlines the selection process. Following screening of electronic medical records for all 358 patients, 141 were classed as ineligible and subsequently excluded. This comprised patients who had either died $(n=129)$ or those $<18$ years of age $(n=1)$, as well as patients with a COVID-19 negative diagnosis $(n=11)$, defined as individuals with presenting complaints initially ascribed to SARS-CoV-2 infection, but which were later attributed to non-COVID-19 causes. The remaining 217 patients were deemed eligible for this study. However, 15 were not invited to participate due to overarching causes for exclusion. This included patients who were unable to consent, such as those with severe cognitive impairment $(n=9)$, severe learning disabilities $(n=3)$ or patients under intensive hospitalisation $(n=1)$. Additionally, imprisoned individuals $(\mathrm{n}=1)$ and those 


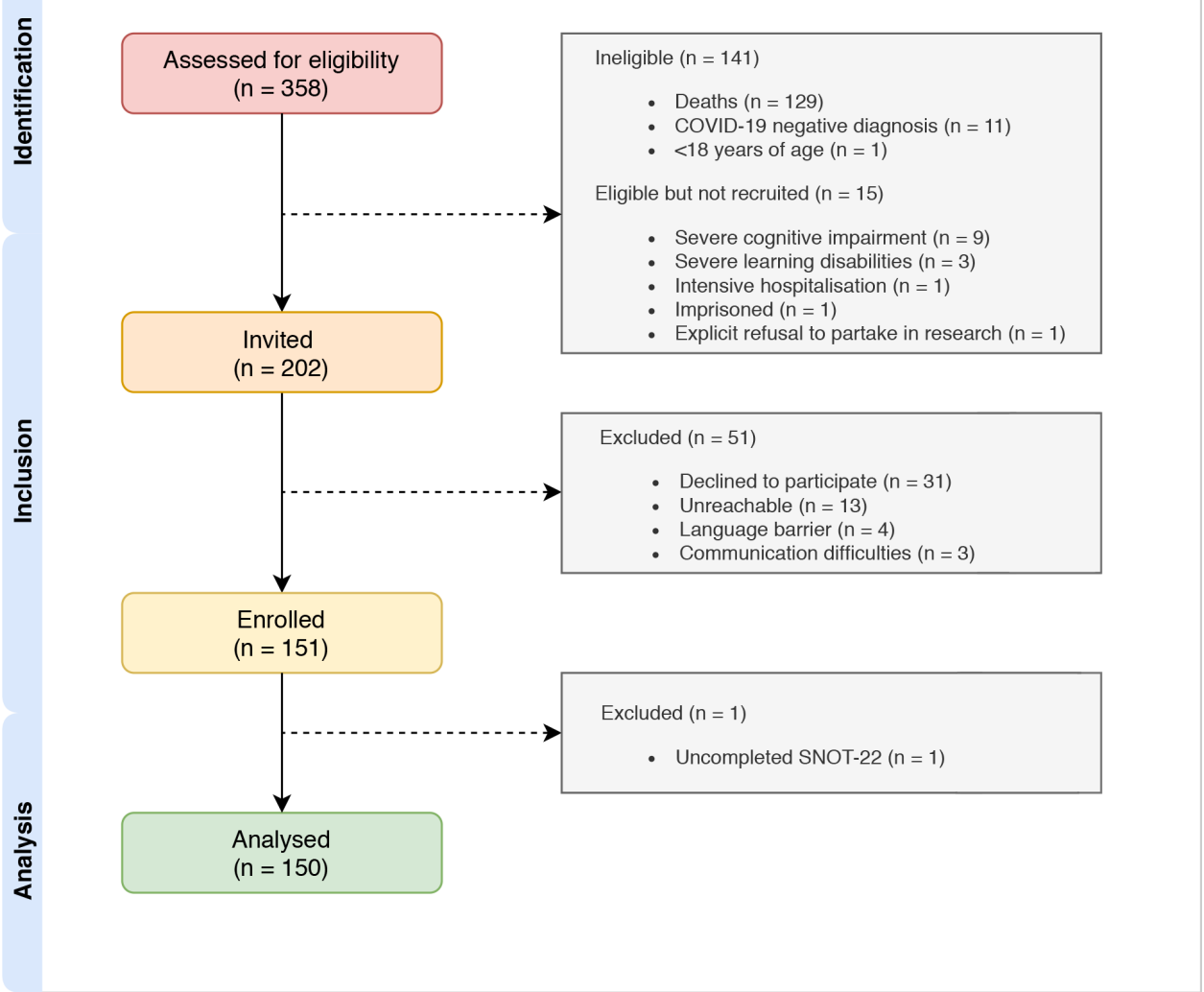

Figure 1 Flow chart depicting stages of patient identification, inclusion and analysis. SNOT-22, Sino-Nasal Outcome Test-22.

with explicit refusal to partake in research as recorded in the patient notes $(n=1)$ were excluded. Of the 202 patients contacted and invited to participate, 51 were excluded. This included unreachable patients $(n=13)$, defined as those unable to be contacted despite $>3$ separate attempts $(\mathrm{n}=5)$ and those with invalid contact details $(n=8)$. Patients with communication difficulties $(n=3)$ referring to aphonic individuals $(n=2)$ or patients with hearing impairments $(n=1)$ preventing completion of the questionnaires. Responses were received from 151/202 invited participants, thereby resulting in a response rate of $74.8 \%$. One patient who did not provide any answers to the SNOT-22 was excluded.

\section{Demographics and characteristics}

A final population of 150 subjects ( 102 male and 48 female, male:female ratio of approximately 2:1) was obtained. The majority of patients had laboratory-confirmed COVID-19 $(\mathrm{n}=147)$ and three patients had a presumptive diagnosis based on clinical criteria. Median time from infection was 264.5 days (range 215-318). Detailed demographics and baseline characteristics of the population are summarised in table 1.

\section{Sino-Nasal Outcome Test-22}

A total of 150 patients completed the SNOT-22 and the median total score for the whole population was 17.0 (Q1-Q3: $6.0-36.3 ; 95 \%$ CI 13.0 to 22.0). As depicted in figure 2, the five most prevalent SNOT-22 problems were: wake up tired $(101 / 149,67.8 \%)$, fatigue $(97 / 147$,
$66.0 \%)$, lack of a good night's sleep (98/149, 65.8\%), reduced productivity $(97 / 148,65.5 \%)$ and wake up at night $(94 / 149,63.1 \%)$. Wake up tired, fatigue and lack of a good night's sleep were also among the problems most frequently reported to affect patient health the most (figure 3). $14.1 \%(21 / 149)$ of patients reported to have decreased sense of smell/taste in the SNOT-22 (score $\geq 1$ at the corresponding item), of which the severity was very mild in $4.0 \%$, mild in $4.7 \%$, moderate in $2.7 \%$ and severe in $2.7 \%$. Two individuals were classed as pre-existing $\mathrm{OD} \pm \mathrm{GD}$ based on evidence of iatrogenic causes and age-related olfactory loss predating COVID-19 infection and hospitalisation. This led to a total of 19/149 patients $(12.8 \%)$ with reported decreased smell/taste in the context of COVID-19. Only 2/18 (11.1\%) had sought treatment: one patient did olfactory training and the other patient did not specify. Characteristics of OD and GD are reported in table 2.

Patients with $\mathrm{OD} \pm \mathrm{GD}$ demonstrated a statistically significant higher median total SNOT-22 score (46.1; Q1-Q3: 23.0-60.0; 95\% CI 23.0 to 60.0) than those without (16.0; Q1-Q3: 5.0-30.5; 95\% CI 12.0 to 18.0) $(\mathrm{p}=0.0002)$ and their scores were higher across all SNOT-22 domains ${ }^{24}$ except one (extranasal rhinologic symptoms) (table 3). Total SNOT-22 scores were found to improve over time in patients without OD or GD ( $\mathrm{p}=0.0327)$, although this was not observed in patients with $\mathrm{OD} \pm \mathrm{GD}(\mathrm{p}=0.4977)$ (figure 4). Comparisons of the demographics of the two subgroups found no influence of age, sex, ethnicity or smoking status (have smoked 
Table 1 Detailed characteristics of the population

\begin{tabular}{|c|c|c|c|c|}
\hline & Total population & Patients without OD or GD & Patients with $\mathrm{OD} \pm \mathrm{GD}$ & \\
\hline & $(n=150)$ & $(n=129)$ & $\begin{array}{l}(n=19) \\
\end{array}$ & $P$ value \\
\hline Age, $($ mean $\pm S D)$, years & $58.0 \pm 15.9$ & $57.8 \pm 16.4$ & $59.6 \pm 11.8$ & 0.5773 \\
\hline \multicolumn{5}{|l|}{ Age groups, $n(\%)$} \\
\hline $18-30$ & $5(3.3)$ & $5(3.9)$ & $0(0)$ & \\
\hline $31-40$ & $20(13.3)$ & $18(14.0)$ & $2(10.5)$ & \\
\hline $41-50$ & $25(16.7)$ & $21(16.3)$ & $3(15.8)$ & \\
\hline $51-60$ & $23(15.3)$ & $21(16.3)$ & $2(10.5)$ & \\
\hline $61-70$ & 48 (32.0) & $37(28.7)$ & $11(57.9)$ & \\
\hline $71-80$ & $15(10.0)$ & $14(10.9)$ & $0(0)$ & \\
\hline $81-90$ & $12(8.0)$ & $11(8.5)$ & $1(5.3)$ & \\
\hline$>90$ & $2(1.3)$ & $2(1.6)$ & $0(0)$ & \\
\hline \multicolumn{5}{|l|}{ Sex, n (\%) } \\
\hline Male & $102(68.0)$ & $90(69.8)$ & $11(57.9)$ & 0.3032 \\
\hline Female & $48(32.0)$ & 39 (30.2) & $8(42.1)$ & \\
\hline \multicolumn{5}{|l|}{ Ethnicity, n (\%)* } \\
\hline White & $80(58.8)$ & $68(58.6)$ & $11(61.1)$ & \\
\hline BAME & $56(41.2)$ & $48(41.4)$ & 7 (38.9) & $>0.9999$ \\
\hline Missing & 14 & 13 & 1 & \\
\hline \multicolumn{5}{|l|}{ Smoking status, $\mathrm{n}(\%)^{*}$} \\
\hline Never smoked & $72(65.5)$ & $64(66.7)$ & $7(53.8)$ & \\
\hline Have smoked & $38(34.5)$ & $32(33.3)$ & $6(46.2)$ & \\
\hline Current & $10(9.1)$ & $9(9.4)$ & $1(7.7)$ & 0.3699 \\
\hline Quit & $28(25.5)$ & $23(24.0)$ & $5(38.5)$ & \\
\hline Missing & 40 & 33 & 6 & \\
\hline Highest CRP value (mean $\pm S D), \mathrm{mg} / \mathrm{L}$ & $170.9 \pm 135.6$ & $174.5 \pm 139.5$ & $158.0 \pm 109.5$ & 0.9282 \\
\hline \multicolumn{5}{|l|}{ Intubation and ventilation, $\mathrm{n}(\%)^{*}$} \\
\hline No & $52(57.8)$ & $44(55.7)$ & $6(66.7)$ & \\
\hline Yes & $38(42.2)$ & $35(44.3)$ & $3(33.3)$ & 0.7263 \\
\hline Missing & 60 & 50 & 10 & \\
\hline \multicolumn{5}{|l|}{ Oxygen supplementation, $\mathrm{n}(\%)^{*}$} \\
\hline No & $20(17.2)$ & $18(17.8)$ & $1(7.1)$ & 0.4599 \\
\hline Yes & $96(82.8)$ & $83(82.2)$ & $13(92.9)$ & \\
\hline Missing & 34 & 28 & 5 & \\
\hline
\end{tabular}

Percentages may not total $100.0 \%$ due to rounding.

*Missing data have been reported but were not used in the calculation of percentages (valid percent).

BAME, black, Asian and minority ethnic; $C R P, C$ reactive protein; $O D \pm G D$, olfactory and/or gustatory dysfunction.

vs never smoked) on the development of $\mathrm{OD} \pm \mathrm{GD}(\mathrm{p}>0.05)$ (table 1). Similarly, no statistically significant association was observed between $\mathrm{OD} \pm \mathrm{GD}$ and other characteristics recorded during hospitalisation, such as highest $\mathrm{C}$ reactive protein (CRP) value, requirement for intubation and ventilation, or oxygen supplementation $(\mathrm{p}=0.9282,0.7263$ and 0.4599 , respectively).

\section{EQ-5D-5L}

A total of 149 patients completed the EQ-5D-5L and the median value for the total population was 0.80 (Q1-Q3:
$0.53-0.94 ; 95 \%$ CI 0.73 to 0.86 ). Patients with $\mathrm{OD} \pm \mathrm{GD}$ had a lower median EQ-5D-5L value (0.70; Q1-Q3: 0.38$0.83 ; 95 \%$ CI 0.38 to 0.83 ) compared with those without OD or GD (0.83; Q1-Q3: $0.61-0.94 ; 95 \%$ CI 0.75 to 0.89$)$; however, the difference was not statistically significant $(p=0.0627)$. Time from infection (the number of days between the date of the patient's first COVID-19 positive swab or their onset of COVID-19 symptoms, and the date at which the questionnaire was administered) was not found to be correlated to EQ-5D-5L value in both patients 

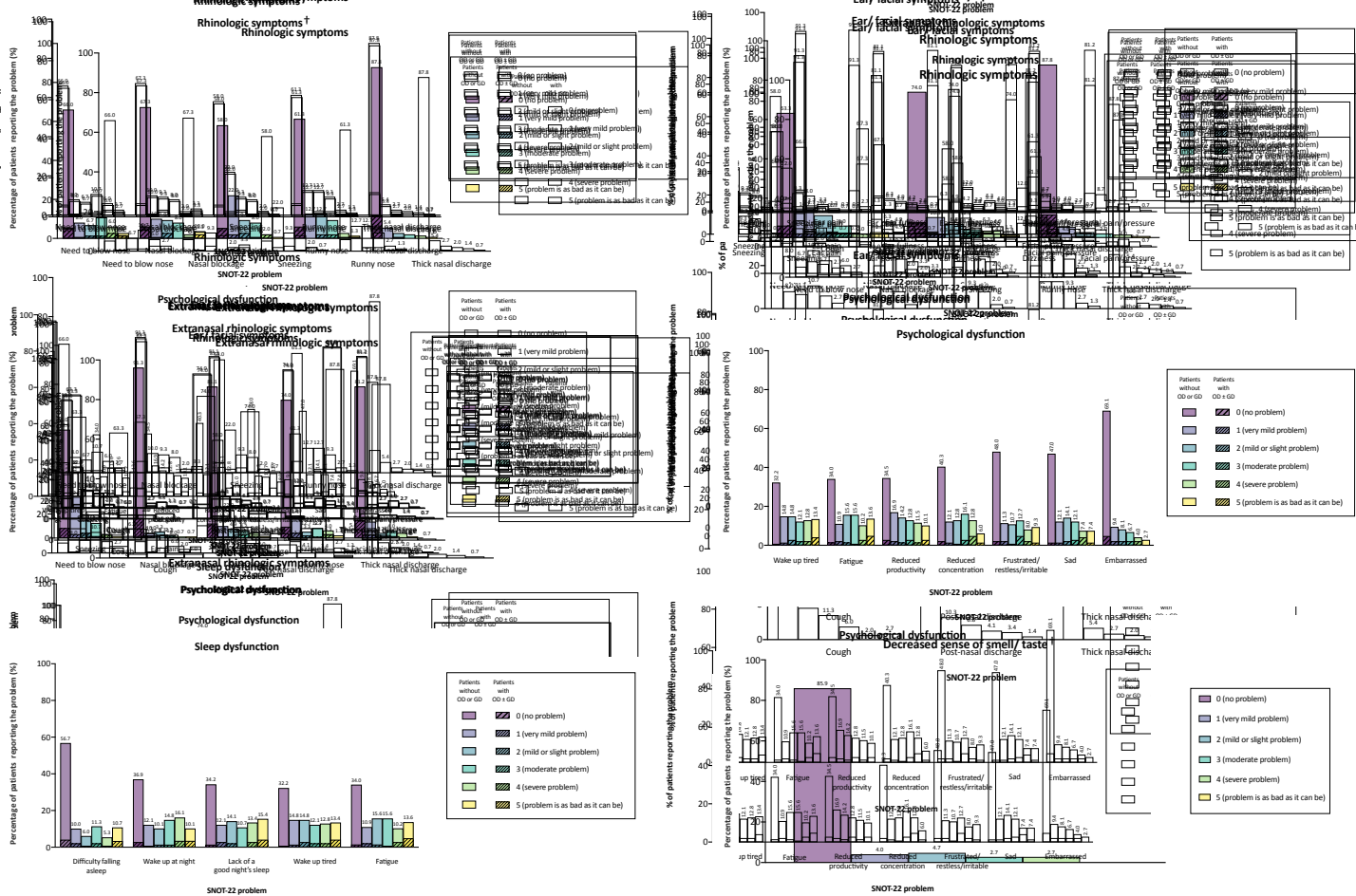

Figure 2 Prevalence of Sino-Nasal Outcome Test-22 (SNOT-22) problems stratified by severity and categorised by domain. †The item 'decreased sense of smell/taste' was excluded from the rhinologic symptoms domain and presented separately, given olfactory and/or gustatory dysfunction $(\mathrm{OD} \pm \mathrm{GD})$ status was used as a subgroup in the subanalysis.

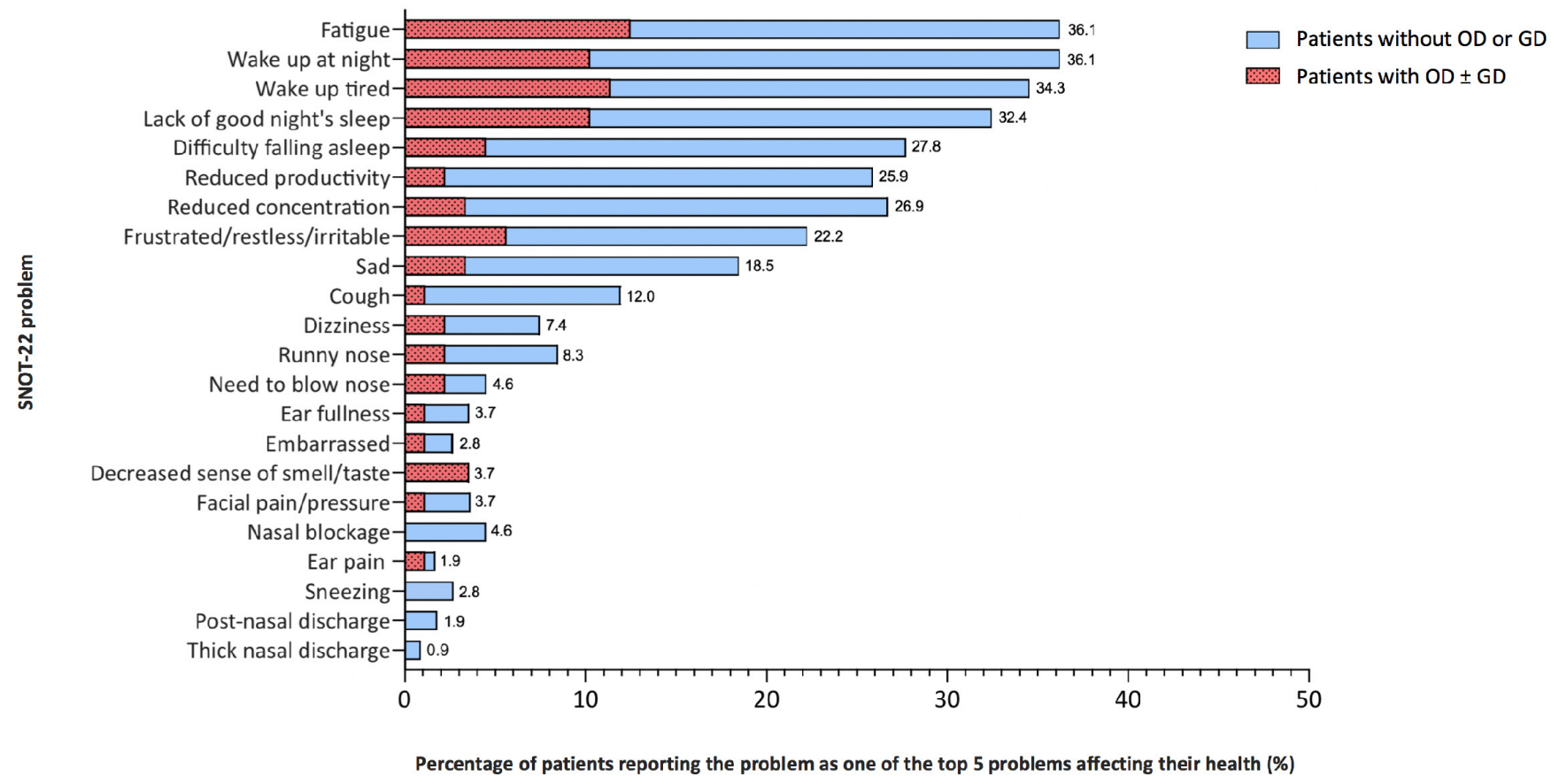

Figure 3 SNOT-22 problems reported to most greatly affect patient health. OD $\pm \mathrm{GD}$, olfactory and/or gustatory dysfunction; SNOT-22, Sino-Nasal Outcome Test-22. 
Table 2 Prevalence and characteristics of olfactory and gustatory disorders

\begin{tabular}{|c|c|}
\hline & $\begin{array}{l}\text { Total responses } \\
(n=149)\end{array}$ \\
\hline \multicolumn{2}{|l|}{ Prevalence, n (\%) } \\
\hline Total reporting decreased smell/taste & $21(14.1)$ \\
\hline In the context of COVID-19 & $19(12.8)$ \\
\hline Pre-existing & $2(1.3)$ \\
\hline \multirow[t]{2}{*}{ No OD or GD } & $128(85.9)$ \\
\hline & $\begin{array}{l}\text { Analysed population } \\
\text { with } O D \pm G D(n=19)^{*}\end{array}$ \\
\hline \multicolumn{2}{|l|}{ Type of dysfunction reported, n (\%) } \\
\hline OD and GD & $15(78.9)$ \\
\hline Only OD & $4(21.1)$ \\
\hline Only GD & $0(0)$ \\
\hline Parosmia† & $3(16.7)$ \\
\hline Parageusia† & $5(27.8)$ \\
\hline Phantosmia† & $2(11.1)$ \\
\hline Phantogeusia† & $0(0)$ \\
\hline \multicolumn{2}{|l|}{$\mathrm{OD} \pm \mathrm{GD}$ characteristics, $\mathrm{n}(\%)$} \\
\hline Constant† & $14(77.8)$ \\
\hline Fluctuant $†$ & $4(22.2)$ \\
\hline Isolated OD†‡ & $1(5.3)$ \\
\hline Isolated GD†‡ & $0(0)$ \\
\hline \multicolumn{2}{|l|}{ Treatment, $\mathrm{n}(\%) \dagger$} \\
\hline Have not sought treatment & $16(88.9)$ \\
\hline Have sought treatment & $2(11.1)$ \\
\hline
\end{tabular}

*Analyses performed on population following application of exclusion criteria (excludes pre-existing $\mathrm{OD} \pm \mathrm{GD}$ ). †Valid percentages calculated based on subjects who provided responses to the question $(n=18)$. Missing responses were not included in the calculations.

\#'Isolated' OD or GD defined as decreased sense of smell/taste in the absence of any other SNOT-22 problem.

$\mathrm{OD} \pm \mathrm{GD}$, olfactory and/or gustatory dysfunction; SNOT-22, SinoNasal Outcome Test-22.

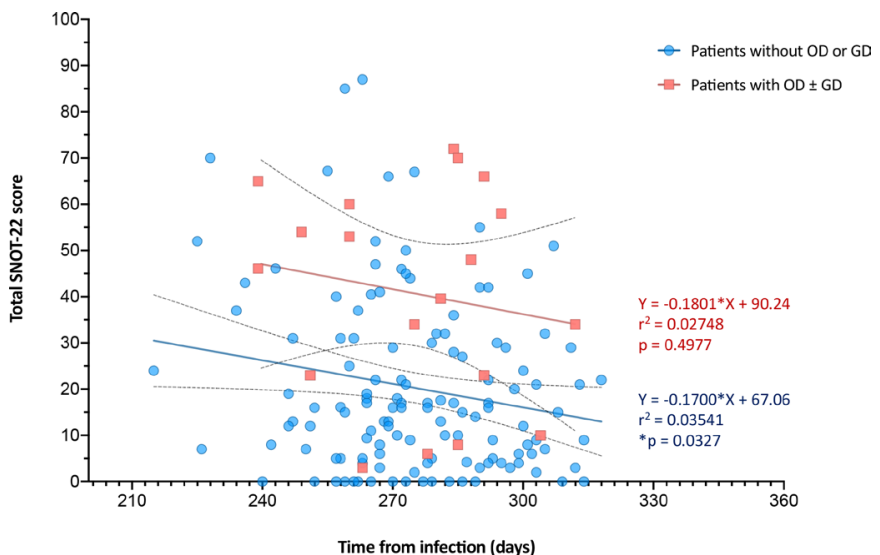

Figure 4 Linear regression analysis of subgroup changes in total SNOT-22 scores over time. Dashed lines denote $95 \% \mathrm{Cl}$. *Significant $p$ values. Level of significance $p<0.05$. $\mathrm{OD} \pm \mathrm{GD}$, olfactory and/or gustatory dysfunction; SNOT-22, Sino-Nasal Outcome Test-22.

with $\mathrm{OD} \pm \mathrm{GD}(\mathrm{p}=0.8693)$ and those without $(\mathrm{p}=0.5371)$ (figure 5).

\section{DISCUSSION}

This is the first study to evaluate the long-term prevalence of $\mathrm{OD} \pm \mathrm{GD}$ in a group of previously hospitalised patients with COVID-19.

The prevalence of $\mathrm{OD} \pm \mathrm{GD}$ in our studied population was $12.8 \%$. This is considerably lower than that of surveys conducted in hospitalised patients in Europe $(35.0 \%-80.6 \%$ for OD and $21.0 \%-90.3 \%$ for GD within 1 month), ${ }^{25-27}$ and in other countries such as Turkey $(42.3 \%$ for $\mathrm{OD} \pm \mathrm{GD}),{ }^{28}$ and Brazil $(64.6 \%$ and $66.7 \%$ for $\mathrm{OD}$ and GD, respectively, at follow-up of $15-55$ days).$^{29}$ The longer follow-up at which our study has been conducted could explain the lower rate of observed chemosensory alteration in our population, whereby recovery of $\mathrm{OD} / \mathrm{GD}$ is expected to happen over time in some patients. This is supported by a recent French study which found that $24.0 \%$ of non-severe COVID-19 subjects reported persistent OD/GD 7 months after symptom

Table 3 Subgroup differences in median total SNOT-22 score for each domain

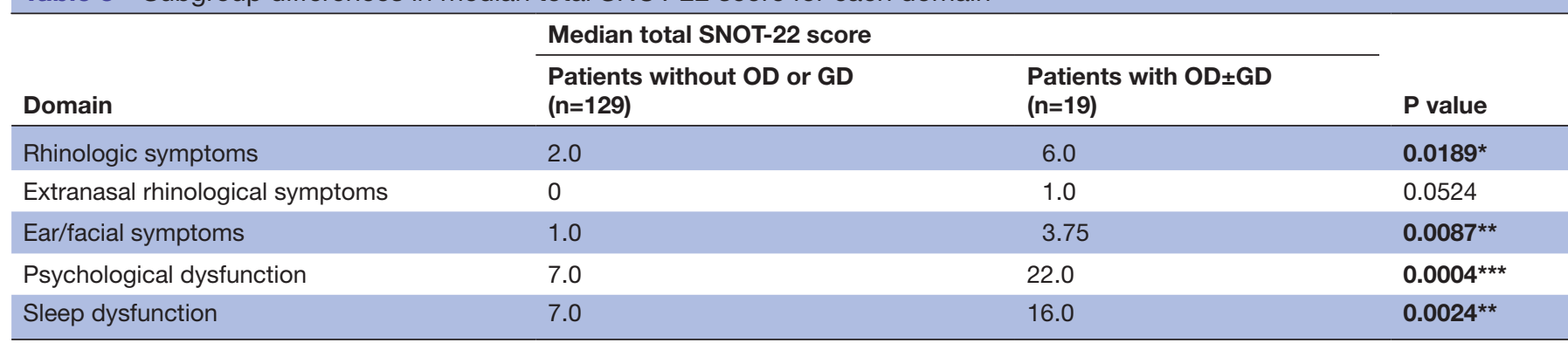

Significant $p$ values in bold. Level of significance ${ }^{*} p<0.05,{ }^{* *} p<0.01,{ }^{* * *} p<0.001$.

$\mathrm{OD} \pm \mathrm{GD}$, olfactory and/or gustatory dysfunction; SNOT-22, Sino-Nasal Outcome Test-22. 


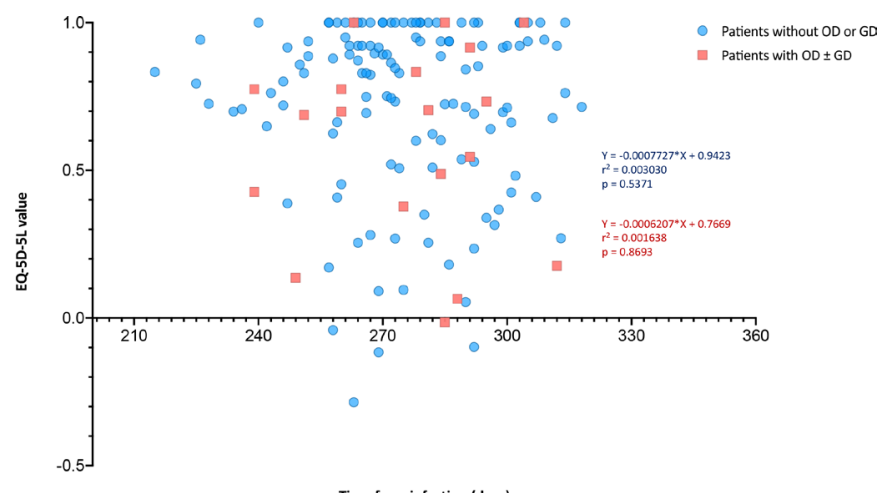

Figure 5 Linear regression analysis of EQ-5D-5L value and time from infection in patients with $\mathrm{OD} \pm \mathrm{GD}$ and patients without $\mathrm{OD}$ or $\mathrm{GD}$. $\mathrm{OD} \pm \mathrm{GD}$, olfactory and/or gustatory dysfunction; EQ-5D-5L, EuroQoL 5-Dimension 5-Level.

onset. ${ }^{30}$ Interestingly, our prevalence of $12.8 \%$ is similar to that observed by Lee $e t a \hat{l}^{1}(15.3 \%)$ in a large Korean cohort of 3191 patients with varying COVID-19 severity at 1 month, but it is relatively higher than that observed by Mao $e t \mathrm{al}^{12}$ in a population of 214 acutely hospitalised patients with COVID-19 $(5.1 \%$ and $5.6 \%$ with OD and GD, respectively). A selection bias could have potentially influenced the observed lower prevalence. Most surveys investigating OD/GD in COVID-19 subjects have been conducted on patients with mild-to-moderate symptoms. ${ }^{511}$ 32-34 In this regard, higher prevalence of anosmia has been noted in milder individuals, along with a significantly increased risk of self-reported olfactory loss in outpatients compared with hospitalised patients. ${ }^{35}$ This is reflected in the most recent studies on long-term COVID19 -related $\mathrm{OD} \pm \mathrm{GD}$. In one study, $48.0 \%$ and $38.5 \%$ of nonhospitalised COVID-19 subjects reported persistent OD and GD, respectively, at 8 months follow-up. ${ }^{36}$ Similarly, $21.3 \%$ of subjects reported $\mathrm{OD} \pm \mathrm{GD}$ in another study of mild-to-moderate symptomatic patients at 1 year. ${ }^{37}$ These values were notably higher than our described prevalence despite the longer follow-up times, thus suggesting that selection bias may produce the observed disparities in reported long-term $\mathrm{OD} \pm \mathrm{GD}$ prevalence.

Additionally, it is important to consider the possible contribution of COVID-19 variants to such disparities due to their potential differing effects on olfaction. Genetic, structural and epidemiological data have shown that a single nucleotide polymorphism from D614 to G614 (D614G mutation) in the spike protein of SARS-CoV-2 may enhance chemosensory impairment, resulting in increased prevalence of COVID-19-related $\mathrm{OD} \pm \mathrm{GD}{ }^{38} 39$ With the presence of different viral strains and potentially uncharacterised host and viral variants, such factors may have therefore contributed to the different incidences of $\mathrm{OD} \pm \mathrm{GD}$ observed between countries.

In our population, OD was associated with GD in most of the cases $(78.9 \%)$, while none of the subjects reported GD only. This reflects what has extensively been reported in previous studies ${ }^{804041}$ and confirms that GD is usually linked to an impairment of retronasal olfaction rather than impairment of gustation itself. Nonetheless, although less common, isolated GD has been described in patients with COVID-19. ${ }^{42}$

Despite the extensive literature available on quantitative changes in smell and taste, qualitative alterations of smell and taste in COVID-19 have been seldom explored. In our study, $16.7 \%$ of patients had parosmia (distortions in smell) while $27.8 \%$ had parageusia (distortions in taste). A similar prevalence $(15.0 \%)$ of parosmia was reported by Gorzkowski $e t a l^{43}$ although a higher rate of $32.4 \%$ was previously described by Lechien et al. ${ }^{5}$ Prevalence of COVID-19-related parageusia vary widely in the literature, but a recent meta-analysis of 8438 patients with COVID-19 from 13 countries revealed a pooled prevalence of $38.2 \%$ (95\% CI $24.0 \%$ to $53.6 \%$ ), ${ }^{44}$ which is higher than that observed in our study. The differences observed between studies could partly reflect inherent biases in the composition of sampled populations. Additionally, a cultural variability in taste appreciation or perception has been reported to exist in COVID-19 positive subjects with a different cultural background. ${ }^{45}$ Phantosmia (the detections of smells not present within the environment) was reported in $11.1 \%$ of our study participants. A similar prevalence was reported by Lechien et $a \tilde{\varphi}$ and Gorzkowski et al. ${ }^{43}$ No cases of phantogeusia (abnormal taste in the mouth in the absence of any stimulus) were recorded in our population and based on the current published literature, prevalence of phantogeusia in COVID-19 subjects is unknown. In line with previous findings, ${ }^{53}$ most of our participants $(77.8 \%)$ reported constant $\mathrm{OD} \pm \mathrm{GD}$, suggesting that the driving mechanism leading to persistent chemosensory dysfunction is sensorineural.

No statistically significant association between persistent $\mathrm{OD} \pm \mathrm{GD}$ and age, smoking status, highest CRP value, intubation and ventilation, or oxygen supplementation was found in our study, thus corroborating results from multiple studies. ${ }^{29} 30324346-50$ Similarly, sex did not demonstrate any influence on the prevalence of persistent $\mathrm{OD} \pm \mathrm{GD}$ in our study, which is in line with previous studies conducted worldwide. ${ }^{732} 43475152$ Nonetheless, several authors have observed a significantly higher prevalence of $\mathrm{OD} \pm \mathrm{GD}$ in women, ${ }^{5314653}$ with some reports suggesting that being female is a risk factor for prolonged recovery from chemosensory dysfunction. ${ }^{26} 2948$ However, the female predominance observed from such studies may be attributed to the differences in the sampled populations (hospitalised vs mild-to-moderate) or in the gender composition. In fact, previous studies on COVID-19 hospitalised patients have demonstrated a lower prevalence of female patients, ${ }^{54}$ which is confirmed by the male:female ratio in our population $(2: 1)$. Moreover, women tend to outperform men on olfactory assessment and in their capacity to perceive OD, which could lead to disproportionately increased prevalence seen in females. ${ }^{556}$

Our study included a more ethnically diverse population in comparison to more geographically limited studies conducted on cohorts of the same ethnic background. 
Despite this, we found no statistically significant association between ethnicity and $\mathrm{OD} \pm \mathrm{GD}$, in contrast to what was reported by Doty ${ }^{57}$ before the pandemic that ethnic minorities are more at risk of developing chemosensory dysfunction.

In this study, the majority of patients reporting decreased sense of smell/taste had very mild or mild impairment as opposed to moderate or severe impairment. Decreased sense of smell/taste was also not frequently ranked within the top five of their most important items, suggesting that chemosensory impairment was not of their greatest concern, if compared with other residual symptoms listed in the SNOT-22. This is an expected finding, considering previous studies which show that hospitalised patients are less likely to report olfactory loss compared with patients with milder course, ${ }^{35}$ possibly due to the presence of more prominent symptoms. However, while $\mathrm{OD} \pm \mathrm{GD}$ severity was not largely found to be profound in this study, it should be noted that patients with $\mathrm{OD} \pm \mathrm{GD}$ had a significantly higher median total SNOT-22 score than those without, with the score only improving over time for the latter subgroup. This corresponds to a greater health burden and subsequent poorer QoL among those affected with chemosensory impairments, as exemplified in a recent study by Chary et al. ${ }^{46}$ More importantly, it reflects the ongoing health burden in patients with $\mathrm{OD} \pm \mathrm{GD}$, which has previously been depicted to a similar effect. ${ }^{51}$ Analysis of the SNOT-22 items demonstrated intrinsic psychological and sleep dysfunction in our population, where the items wake up tired, fatigue and lack of a good night's sleep were three of the most commonly ticked 'important items' (maximum of five items). While this highlights some of the long-term manifestations of COVID-19, now called 'long-COVID', ${ }^{58}$ further subanalysis revealed that $\mathrm{OD} \pm \mathrm{GD}$ reduced QoL in nearly all domains, especially that of psychological dysfunction, when compared with patients without OD or GD. Recent studies have supported this, with emphasis on both the direct and indirect negative effects of COVID-19-related OD on psychological well-being. In one study, $15.8 \%$ of patients with COVID-19 with OD reported depression due to their smell loss ${ }^{59}$ whereas in a separate study, $28.2 \%$ had increased anger as a secondary effect. ${ }^{60} \mathrm{~A}$ more recent study reported that chemosensory disturbance in mildly symptomatic patients with COVID-19 was associated with emotional distress and depression, despite over a year since the onset of their COVID-19 infection. ${ }^{61}$ Interestingly, long-lasting fatigue has also been found to be significantly associated with persistent $\mathrm{OD} \pm \mathrm{GD}{ }^{33}$ Taken together, our findings therefore highlight the negative long-term effects of persistent $\mathrm{OD} \pm \mathrm{GD}$ on $\mathrm{QoL}$.

Conversely, based on subgroup analysis of EQ-5D-5L values, we did not observe any difference in healthrelated QoL between those with $\mathrm{OD} \pm \mathrm{GD}$ and those without. More importantly, EQ-5D-5L value did not improve with time and was not influenced by the presence of a chemosensory alteration. One possible explanation for these results is interpatient variability. Given that the EQ-5D-5L is nonspecific to COVID-19 and captures responses based on overall QoL on the day of questioning, patients' responses could have been influenced by other factors. The questionnaire also may not have been sensitive enough to differentiate the problems experienced by patients with $\mathrm{OD} \pm \mathrm{GD}$. Alternatively, the lack of any significant difference in EQ-5D-5L values between these two subgroups may reflect the residual difficulties of long-COVID which are common to many patients with COVID-19, regardless of anosmia status.

\section{Strengths and limitations}

To our knowledge, this represents the first study to have determined the prevalence of $\mathrm{OD} \pm \mathrm{GD}$ in a cohort of previously hospitalised patients with COVID-19 at 1 year following infection. We have, therefore, provided a more current insight into both the persistence and the scale of OD and GD from a long-term perspective, and the impact on patients' QoL and well-being. Our cohort of previously hospitalised patients with COVID-19 also adds value by highlighting differences in $\mathrm{OD} \pm \mathrm{GD}$ prevalence in different populations, given that current existing studies have predominantly been based on mild-to-moderately affected patients or healthcare workers.

The prevalence of OD and GD observed in our study refers to a single-centre population of previously hospitalised patients with COVID-19. Our findings, therefore, may not be directly comparable or generalisable to those reported for mild-to-moderate symptomatic COVID-19 subjects in the general community. There is also the possibility of misdiagnosis, especially with the three clinically confirmed patients with COVID-19, although this is unlikely considering the surging number of COVID-19 cases at the time of their presentation. Without baseline data, we were unable to determine the extent to which the impairments in $\mathrm{OD} \pm \mathrm{GD}$ patients were new onset or more chronic, or whether there was any previous improvement of chemosensory function. Lastly, as in other COVID-19 studies, patients with $\mathrm{OD} \pm \mathrm{GD}$ were identified through subjective, self-reported questionnaires. These have a low correlation with psychophysical measurements, ${ }^{62}$ and findings derived from these surveys cannot be compared with studies which have used objective tests, such as Sniffin' sticks. However, given that psychophysical testing has not been available or feasible in many countries during the pandemic, we believe that, in an emergency condition, self-rated symptoms remain of value. ${ }^{63}$

\section{Clinical implications of this study}

A proportion of previously hospitalised patients with COVID-19 may continue to experience persistent $\mathrm{OD} \pm \mathrm{GD}$ long term, especially when this is not treated. With over 9.3 million COVID-19 positive cases in the UK at the time of writing, ${ }^{64}$ and with numbers likely to increase including untested asymptomatic individuals and those with milder disease, our study demonstrates the relevance of $\mathrm{OD} \pm \mathrm{GD}$ and its place as a key manifestation of longCOVID. OD \pm GD impacts QoL and can have a potentially 
substantial long-term burden on patients and healthcare resources.

Our study suggests that persistent COVID-19-related chemosensory dysfunction requires increased holistic support. This includes safety counselling, psychological therapy, coping strategies and patient support groups to aid patients in the management of their $\mathrm{OD} \pm \mathrm{GD}$, but concurrent rehabilitation such as olfactory training should also be considered, given the evidence base supporting its effectiveness in post-viral olfactory loss. ${ }^{65-68}$ It should also be noted that there are currently ongoing clinical trials assessing other interventions such as antiinflammatory agents, nasal/oral steroids and even intranasal photobiomodulation therapy. ${ }^{69}$ However, while these could play supportive roles in the potential recovery of COVID-19-related $\mathrm{OD} \pm \mathrm{GD}$, further research regarding their safety and efficacy will be needed, alongside additional studies investigating the impact of such modalities on patient QoL.

\section{CONCLUSIONS}

Up to a year following infection, $12.8 \%$ of previously hospitalised patients with COVID-19 in London reported persistent chemosensory dysfunction. COVID-19-related $\mathrm{OD} \pm \mathrm{GD}$ reduces both $\mathrm{QoL}$ and psychological wellbeing, and this does not improve over time, creating an important health burden. With the number of patients seeking treatment expected to rise, developing new therapeutic treatments will be important in the future, as well as providing adequate patient support for now.

Contributors DC and HQMT conceptualised and designed the study. HQMT and ALP drafted the manuscript. HQMT performed data acquisition, statistical analyses and production of figures and tables. All authors (HQMT, ALP, PJA and DC) contributed to the interpretation of the results and critically revised the manuscript. All authors approved the final manuscript. The corresponding author (HQMT) attests that all listed authors meet authorship criteria and that no others meeting the criteria have been omitted. HQMT and DC are the guarantors.

Funding The authors have not declared a specific grant for this research from any funding agency in the public, commercial or not-for-profit sectors.

Competing interests None declared.

Patient consent for publication Not applicable.

Ethics approval This study involves human participants and was approved by Research Ethics Committee and the UCL Joint Research Office (REC reference: 14/ SC/1180; IRAS project ID: 156511).

Provenance and peer review Not commissioned; externally peer reviewed.

Data availability statement № data are available. No additional data are available.

Supplemental material This content has been supplied by the author(s). It has not been vetted by BMJ Publishing Group Limited (BMJ) and may not have been peer-reviewed. Any opinions or recommendations discussed are solely those of the author(s) and are not endorsed by BMJ. BMJ disclaims all liability and responsibility arising from any reliance placed on the content. Where the content includes any translated material, BMJ does not warrant the accuracy and reliability of the translations (including but not limited to local regulations, clinical guidelines, terminology, drug names and drug dosages), and is not responsible for any error and/or omissions arising from translation and adaptation or otherwise.

Open access This is an open access article distributed in accordance with the Creative Commons Attribution Non Commercial (CC BY-NC 4.0) license, which permits others to distribute, remix, adapt, build upon this work non-commercially, and license their derivative works on different terms, provided the original work is properly cited, appropriate credit is given, any changes made indicated, and the use is non-commercial. See: http://creativecommons.org/licenses/by-nc/4.0/.

ORCID iDs

Hui Qi Mandy Tan http://orcid.org/0000-0003-1339-3096

Alfonso Luca Pendolino http://orcid.org/0000-0002-6348-5303

Peter J Andrews http://orcid.org/0000-0001-5731-3276

\section{REFERENCES}

1 World Health Organization. WHO Coronavirus (COVID-19) Dashboard [Internet], 2021. Available: https://covid19.who.int [Accessed $10 \mathrm{Nov}$ 2021].

2 Buitrago-Garcia D, Egli-Gany D, Counotte MJ, et al. Occurrence and transmission potential of asymptomatic and presymptomatic SARSCoV-2 infections: a living systematic review and meta-analysis. PLoS Med 2020;17:e1003346.

3 Byambasuren O, Cardona M, Bell K. Estimating the extent of asymptomatic COVID-19 and its potential for community transmission: systematic review and meta-analysis. JAMMI 2020;5:223-34.

4 Struyf T, Deeks JJ, Dinnes J, et al. Signs and symptoms to determine if a patient presenting in primary care or hospital outpatient settings has COVID-19. Cochrane Database Syst Rev 2021;2:CD013665.

5 Lechien JR, Chiesa-Estomba CM, De Siati DR, et al. Olfactory and gustatory dysfunctions as a clinical presentation of mild-to-moderate forms of the coronavirus disease (COVID-19): a multicenter European study. Eur Arch Otorhinolaryngol 2020;277:2251-61.

6 Qiu C, Cui C, Hautefort C, et al. Olfactory and gustatory dysfunction as an early identifier of COVID-19 in adults and children: an international multicenter study. Otolaryngol Head Neck Surg 2020;163:714-21.

7 Moein ST, Hashemian SM, Mansourafshar B, et al. Smell dysfunction: a biomarker for COVID-19. Int Forum Allergy Rhinol 2020;10:944-50.

8 Samaranayake LP, Fakhruddin KS, Mohammad OE, et al. Attributes of dysgeusia and anosmia of coronavirus disease 2019 (COVID-19) in hospitalized patients. Oral Dis 2020. doi:10.1111/odi.13713. [Epub ahead of print: 11 Nov 2020].

9 Andrews PJ, Pendolino AL, Ottaviano G, et al. Olfactory and taste dysfunction among mild-to-moderate symptomatic COVID-19 positive health care workers: an international survey. Laryngoscope Investig Otolaryngol 2020;5:1019-28.

10 Chiesa-Estomba CM, Lechien JR, Radulesco T, et al. Patterns of smell recovery in 751 patients affected by the COVID-19 outbreak. Eur J Neurol 2020;27:2318-21.

11 Lechien JR, Chiesa-Estomba CM, Place S, et al. Clinical and epidemiological characteristics of 1420 European patients with mild-to-moderate coronavirus disease 2019. J Intern Med 2020;288:335-44.

12 Mao L, Jin H, Wang M, et al. Neurologic manifestations of hospitalized patients with coronavirus disease 2019 in Wuhan, China. JAMA Neurol 2020;77:683-90.

13 Croy I, Nordin S, Hummel T. Olfactory disorders and quality of life-an updated review. Chem Senses 2014;39:185-94.

14 Nordin S, Brämerson A. Complaints of olfactory disorders: epidemiology, assessment and clinical implications. Curr Opin Allergy Clin Immunol 2008;8:10-15.

15 Landis BN, Konnerth CG, Hummel T. A study on the frequency of olfactory dysfunction. Laryngoscope 2004;114:1764-9.

16 Devanand DP, Lee S, Manly J, et al. Olfactory identification deficits and increased mortality in the community. Ann Neurol 2015;78:401-11.

17 Schubert CR, Fischer ME, Pinto AA, et al. Sensory impairments and risk of mortality in older adults. J Gerontol A Biol Sci Med Sci 2017;72:710-5.

18 Liu B, Luo Z, Pinto JM, et al. Relationship between poor Olfaction and mortality among community-dwelling older adults: a cohort study. Ann Intern Med 2019;170:673-81.

19 Laudisio A, Navarini L, Margiotta DPE, et al. The association of olfactory dysfunction, frailty, and mortality is mediated by inflammation: results from the InCHIANTI study. J Immunol Res 2019;2019:3128231.

20 Ekström I, Sjölund S, Nordin S, et al. Smell loss predicts mortality risk regardless of dementia conversion. J Am Geriatr Soc 2017;65:1238-43.

21 Pinto JM, Wroblewski KE, Kern DW, et al. Olfactory dysfunction predicts 5-year mortality in older adults. PLoS One 2014;9:e107541. 
22 World Health Organization. Clinical management of severe acute respiratory infection (SARI) when COVID-19 disease is suspected: interim guidance, 2020. Available: https://apps.who.int/iris/handle/ 10665/331446 [Accessed 13 Mar 2020].

23 EuroQol Group. EuroQol--a new facility for the measurement of health-related quality of life. Health Policy 1990;16:199-208.

24 DeConde AS, Mace JC, Bodner T, et al. SNOT-22 quality of life domains differentially predict treatment modality selection in chronic rhinosinusitis. Int Forum Allergy Rhinol 2014;4:972-9.

25 Vacchiano V, Riguzzi P, Volpi L, et al. Early neurological manifestations of hospitalized COVID-19 patients. Neurol Sci 2020;41:2029-31.

26 Meini S, Suardi LR, Busoni M, et al. Olfactory and gustatory dysfunctions in 100 patients hospitalized for COVID-19: sex differences and recovery time in real-life. Eur Arch Otorhinolaryngol 2020;277:3519-23.

27 Beltrán-Corbellini Á, Chico-García JL, Martínez-Poles J, et al. Acuteonset smell and taste disorders in the context of COVID-19: a pilot multicentre polymerase chain reaction based case-control study. Eur J Neurol 2020;27:1738-41.

28 Sayın P, Altınay M, Cınar AS, et al. Taste and smell impairment in critically ill patients with COVID-19: an intensive care unit study. Ear Nose Throat J 2021:100:174S-9.

29 Brandão Neto D, Fornazieri MA, Dib C, et al. Chemosensory dysfunction in COVID-19: prevalences, recovery rates, and clinical associations on a large Brazilian sample. Otolaryngol Head Neck Surg 2021;164:512-8

30 Nguyen NN, Hoang VT, Lagier J-C, et al. Long-term persistence of olfactory and gustatory disorders in COVID-19 patients. Clin Microbiol Infect 2021;27:931-2.

31 Lee $\mathrm{Y}$, Min P, Lee S, et al. Prevalence and duration of acute loss of smell or taste in COVID-19 patients. J Korean Med Sci 2020;35:e174.

32 Boscolo-Rizzo P, Borsetto D, Fabbris C, et al. Evolution of altered sense of smell or taste in patients with mildly symptomatic COVID-19. JAMA Otolaryngol Head Neck Surg 2020;146:729-32.

33 Boscolo-Rizzo P, Polesel J, Spinato G, et al. Predominance of an altered sense of smell or taste among long-lasting symptoms in patients with mildly symptomatic COVID-19. Rhinology 2020;58:524-5.

34 Klein H, Asseo K, Karni N, et al. Onset, duration and unresolved symptoms, including smell and taste changes, in mild COVID-19 infection: a cohort study in Israeli patients. Clin Microbiol Infect 2021;27:769-74.

35 D'Ascanio L, Pandolfini M, Cingolani C, et al. Olfactory dysfunction in COVID-19 patients: prevalence and prognosis for recovering sense of smell. Otolaryngol Head Neck Surg 2021;164:82-6.

36 Biadsee A, Dagan O, Ormianer Z, et al. Eight-month follow-up of olfactory and gustatory dysfunctions in recovered COVID-19 patients. Am J Otolaryngol 2021;42:103065.

37 Boscolo-Rizzo P, Guida F, Polesel J, et al. Self-reported smell and taste recovery in coronavirus disease 2019 patients: a one-year prospective study. Eur Arch Otorhinolaryngol 2022;279:1-6.

38 Butowt R, Bilinska K, Von Bartheld CS. Chemosensory dysfunction in COVID-19: integration of genetic and epidemiological data points to $\mathrm{D} 614 \mathrm{G}$ spike protein variant as a contributing factor. ACS Chem Neurosci 2020;11:3180-4.

39 von Bartheld CS, Hagen MM, Butowt R. The D614G virus mutation enhances anosmia in COVID-19 patients: evidence from a systematic review and meta-analysis of studies from South Asia. ACS Chem Neurosci 2021:12:3535-49.

40 Abalo-Lojo JM, Pouso-Diz JM, Gonzalez F. Taste and smell dysfunction in COVID-19 patients. Ann Otol Rhinol Laryngol 2020;129:1041-2.

41 Klopfenstein T, Kadiane-Oussou NJ, Toko L, et al. Features of anosmia in COVID-19. Med Mal Infect 2020;50:436-9.

$42 \mathrm{Xu} \mathrm{H}$, Zhong L, Deng J. High expression of ACE2 receptor of 2019-nCoV on the epithelial cells of oral mucosa. Int J Oral Sci 2020;12:1-5.

43 Gorzkowski V, Bevilacqua S, Charmillon A. Evolution of olfactory disorders in COVID-19 patients. evolution of olfactory disorders in COVID-19 patients. Laryngoscope 2020;130:2667-73.

44 Agyeman AA, Chin KL, Landersdorfer CB, et al. Smell and taste dysfunction in patients with COVID-19: a systematic review and meta-analysis. Mayo Clin Proc 2020;95:1621-31.

45 Pendolino AL, Ottaviano G, Scarpa B. Characteristics of taste dysfunction in COVID-19 subjects coming from two different countries. J Neuroviro/2021:1-4.
46 Chary E, Carsuzaa F, Trijolet J-P, et al. Prevalence and recovery from olfactory and gustatory dysfunctions in Covid-19 infection: a prospective multicenter study. Am J Rhinol Allergy 2020;34:686-93.

47 Otte MS, Klussmann JP, Luers JC. Persisting olfactory dysfunction in patients after recovering from COVID-19. J Infect 2020;81:e58.

48 Paderno A, Mattavelli D, Rampinelli V, et al. Olfactory and gustatory outcomes in COVID-19: a prospective evaluation in nonhospitalized subjects. Otolaryngol Head Neck Surg 2020;163:1144-9.

49 Ugurlu BN, Akdogan O, Yilmaz YA, et al. Quantitative evaluation and progress of olfactory dysfunction in COVID-19. Eur Arch Otorhinolaryngol 2021;278:2363-9.

50 Sakalli E, Temirbekov D, Bayri E, et al. Ear nose throat-related symptoms with a focus on loss of smell and/or taste in COVID-19 patients. Am J Otolaryngol 2020;41:102622.

51 Otte MS, Eckel HNC, Poluschkin L, et al. Olfactory dysfunction in patients after recovering from COVID-19. Acta Otolaryngol 2020;140:1032-5.

52 Vaira LA, Hopkins C, Petrocelli M, et al. Smell and taste recovery in coronavirus disease 2019 patients: a 60-day objective and prospective study. J Laryngol Otol 2020;134:703-9.

53 Hopkins C, Surda P, Whitehead E, et al. Early recovery following new onset anosmia during the COVID-19 pandemic - an observational cohort study. J Otolaryngol Head Neck Surg 2020;49:26.

54 Peckham H, de Gruijter NM, Raine C, et al. Male sex identified by global COVID-19 meta-analysis as a risk factor for death and ITU admission. Nat Commun 2020;11:6317.

55 Doty RL, Cameron EL. Sex differences and reproductive hormone influences on human odor perception. Physiol Behav 2009:97:213-28.

56 Kosugi EM, Lavinsky J, Romano FR, et al. Incomplete and late recovery of sudden olfactory dysfunction in COVID-19. Braz $J$ Otorhinolaryngol 2020;86:490-6.

57 Doty RL. Chapter 1 - Epidemiology of smell and taste dysfunction. In: Doty RL, ed. Handb clin Neurol. , 2019: 164, 3-13.

58 Mandal S, Barnett J, Brill SE, et al. 'Long-COVID': a cross-sectional study of persisting symptoms, biomarker and imaging abnormalities following hospitalisation for COVID-19. Thorax 2021;76:396-8.

59 Elkholi SMA, Abdelwahab MK, Abdelhafeez M. Impact of the smell loss on the quality of life and adopted coping strategies in COVID-19 patients. Eur Arch Otorhinolaryngol 2021;278:3307-14.

60 AlShakhs A, Almomen A, AlYaeesh I, et al. The association of smel and taste dysfunction with COVID19, and their functional impacts. Indian J Otolaryngol Head Neck Surg 2021:1-6.

61 Boscolo-Rizzo P, Hummel T, Hopkins C, et al. High prevalence of long-term olfactory, gustatory, and chemesthesis dysfunction in post-COVID-19 patients: a matched case-control study with oneyear follow-up using a comprehensive psychophysical evaluation. Rhinology 2021;59:517-27.

62 Bordin A, Mucignat-Caretta C, Gaudioso P, et al. Comparison of self-reported symptoms and psychophysical tests in coronavirus disease 2019 (COVID-19) subjects experiencing long-term olfactory dysfunction: a 6-month follow-up study. Int Forum Allergy Rhinol 2021:11:1592-5.

63 Prajapati DP, Shahrvini B, MacDonald BV, et al. Association of subjective olfactory dysfunction and 12-Item odor identification testing in ambulatory COVID-19 patients. Int Forum Allergy Rhinol 2020;10:1209-17.

64 Cases in the UK | Coronavirus in the UK [Internet]. Available: https:// coronavirus.data.gov.uk/details/cases [Accessed 10 Nov 2021]

65 Levy JM. Treatment recommendations for persistent smell and taste dysfunction following COVID-19-The coming deluge. JAMA Otolaryngol Head Neck Surg 2020;146:733.

66 Whitcroft KL, Hummel T. Clinical diagnosis and current management strategies for olfactory dysfunction: a review. JAMA Otolaryngol Head Neck Surg 2019;145:846-9.

67 Whitcroft KL, Hummel T. Olfactory dysfunction in COVID-19: diagnosis and management. JAMA 2020;323:2512-4.

68 Hummel T, Whitcroft KL, Andrews P, et al. Position paper on olfactory dysfunction. Rhinol Suppl 2017;54:1-30.

69 D'Ascanio L, Vitelli F, Cingolani C, et al. Randomized clinical trial "olfactory dysfunction after COVID-19: olfactory rehabilitation therapy vs. intervention treatment with Palmitoylethanolamide and Luteolin": preliminary results. Eur Rev Med Pharmacol Sci 2021;25:4156-62.

70 Soares LES, Guirado MMG, Berlingieri G, et al. Intranasal photobiomodulation therapy for COVID-19-related olfactory dysfunction: a Brazilian multicenter case series. Photodiagnosis Photodyn Ther 2021;36:102574. 